\title{
A new stenothoid species related to the taxon Raumahara Barnard from Australia (Crustacea, Amphipoda, Gammaridea)
}

\author{
T. Krapp-Schickel ${ }^{1} \&$ H. G. Andres ${ }^{2, *}$ \\ ${ }^{1}$ Pfr. Hoffmannstr. 7a, D-53343 Wachtberg-Adendorf, Germany \\ ${ }^{2}$ Universität Hamburg, Zoologisches Institut und Museum, Martin-Luther-King-Platz 3, \\ D-20146 Hamburg, Germany *
}

\begin{abstract}
Benthic samplings along the southern temperate coast of Australia yielded stenothoid specimens related to the taxon Raumahara Barnard. ?Raumahara virdurorum $\mathrm{sp}$. $\mathrm{n}$. is described, illustrated, and the systematic position within the genus is discussed. Raumahara seems to be a nonmonophyletic group, as not one synapomorphic character can be discerned that exactly fits for each member of this taxon.
\end{abstract}

\section{INTRODUCTION}

G. Hartmann and G. Hartmann-Schröder studied the littoral faunal community along the Australian coasts in $1975 / 76$. We had the opportunity to examine the stenothoid amphipods within the genus Raumahara Barnard, 1972 derived from their samplings. - During a stay at the Victoria Museum, Melbourne, one of us (T. K.-S.) had the good fortune to see the rich amphipod collection there, as well as carry out additional field work in the littoral zone near Melbourne. Additional specimens found that way showed close similarity to the above mentioned material.

Aithough the stenothoid specimens dealt with in this paper are not clearly assignable to Raumahara, they are provisionally placed into this taxon because of pending changes in the generic classification within the Stenothoidae, and as a major reorganization of the genera will be attempted in the near future (T. K.-S. \& G. Poore).

The new species is described and illustrated below, and its interrelationships as well as the systematics of Raumahara will be discussed.

\section{MATERIAL AND METHODS}

The stenothoid, Raumahara-like material studied partly (ca 50 specimens) derived in part from G. Hartmann's and G. Hartmann-Schröder's survey in 1975/76 on the faunal community and biogeography of the littoral polychaetes and ostracods around Australia.

\footnotetext{
- Member of the Taxonomy Group at the Biologische Anstalt Helgoland, Notkestr. 31, D-22607 Hamburg, Germany

- Address for all correspondence

(1) Biologische Anstalt Helgoland, Hamburg
} 
Additional material was collected by T. K.-S. (1997) near Melbourne, Victoria (1 ind.) or was found in the collection of the Victoria Museum, Melbourne (4 specimens and one partly damaged). All specimens were obtained from qualitative samples washed from algae and sediment, respectively. The localities are situated along the southern, temperate coast section from Port Lincoln to Melbourne.

The material is lodged in the Zoologisches Museum Hamburg $(\mathrm{ZMH})$ and the Victoria Museum, Melbourne (VMM).

Specimens were placed in glycerin and studied first under stereo- and phase-contrast microscope in toto, then dissected and stored in Faure's medium.

The following abbreviations are used: A - antenna; art - article; EP - epimeral plate (epimeron); Gn - gnathopod; Ip - inner plate; 1 - left; LL - lower lip (paragnath); Md mandible; Mdi - mandibular incisor; Mdp - mandibular palp; $\mathrm{Mx}$ - maxilla; $\mathrm{Mxp}$ - maxilliped; Op - outer plate; $\mathrm{P}$ - peraeopod; $\mathrm{PR}$ - peraeonite; $\mathrm{r}$ - right; $\mathrm{T}$ - Telson; UL - upper lip (labrum); Up - uropod; UR - urosomite.

\section{SYSTEMATICS}

Raumahara Barnard, 1972

1972 a Raumahara Barnard: 318

1972 b Raumahara - Barnard: 160

1981 Raumahara-Moore: 959

1991 Raumahara - Barnard \& Karaman: 697

Barnard \& Karaman (1991) emphasized the variability within Raumahara, indicating the diversity in characters of generic value. And Barnard (1972 a, b, 1974) himself has already called special attention to the provisional and not phyletic concept of this taxon.

Among the currently recognized five species within the genus Raumahara (cf. Barnard \& Karaman, 1991), R. dertoo Barnard, 1972 a, R. noko Barnard, 1974, and $R$. judithae Moore, 1981 share (1) a vaulted urosomite 1 which is strongly ( $R$. dertoo) or weakly ( $R$. noko, $R$. judithae) overlapping urosomite 2 ; $(2)$ the scarcely produced midcephalic keel above the epistome; (3) one subapical seta on the inner lobe of maxilla 1; (4) a chelate gnathopod 1 . - These characters delimit those species from $R$. rongo Barnard, 1972 b (vs. urosomite 1 without dorsal extension; midcephalic keel strongly produced; maxilla 1 inner plate without seta; gnathopod 1 subchelate).

The mandible palp is present with a rudimentary short article in $R$. noko, while all other species are lacking a palp, or it may not have been seen.

A biarticulate accessory flagellum is present in $R$. noko and $R$. judithae; none observed in $R$. carinata Shoemaker, 1955; in all others one article.

Beyond that, further variabilities in characteristic features are discussed by Moore (1981): mediodorsal swelling of second article of antenna 2 , size of third article of antenna 2 , ocular lobe, number of apical setae on outer plate of maxilla 2, the setation of the in-

Fig. 1. ?Raumahara virdurorum sp. n. - D-H, L, M: holotype, female, ovig., $1.6 \mathrm{~mm}$ - A-C: paratype, female, $1.6 \mathrm{~mm}$. - I, J, K, N: paratype, sex?, $1.8 \mathrm{~mm}$. - A: habitus, fore-part (not levelled). B: cephalon with epistome (lateral view). C: coxa 4 (levelled). D: epimeral plates 1-3, left. E: epimeral plates 2 and 3, right. F: urosome (lateral view). F': uropod 3 (left), outer ramus, distal part. G: antenna 1. $\mathrm{H}$ : antenna 2. I: upper lip. $\mathrm{J}$ and $\mathrm{L}$ : mandible, right. $\mathrm{K}$ : mandible, left, incisor to molar surface. M: lower lip. N: maxilliped 


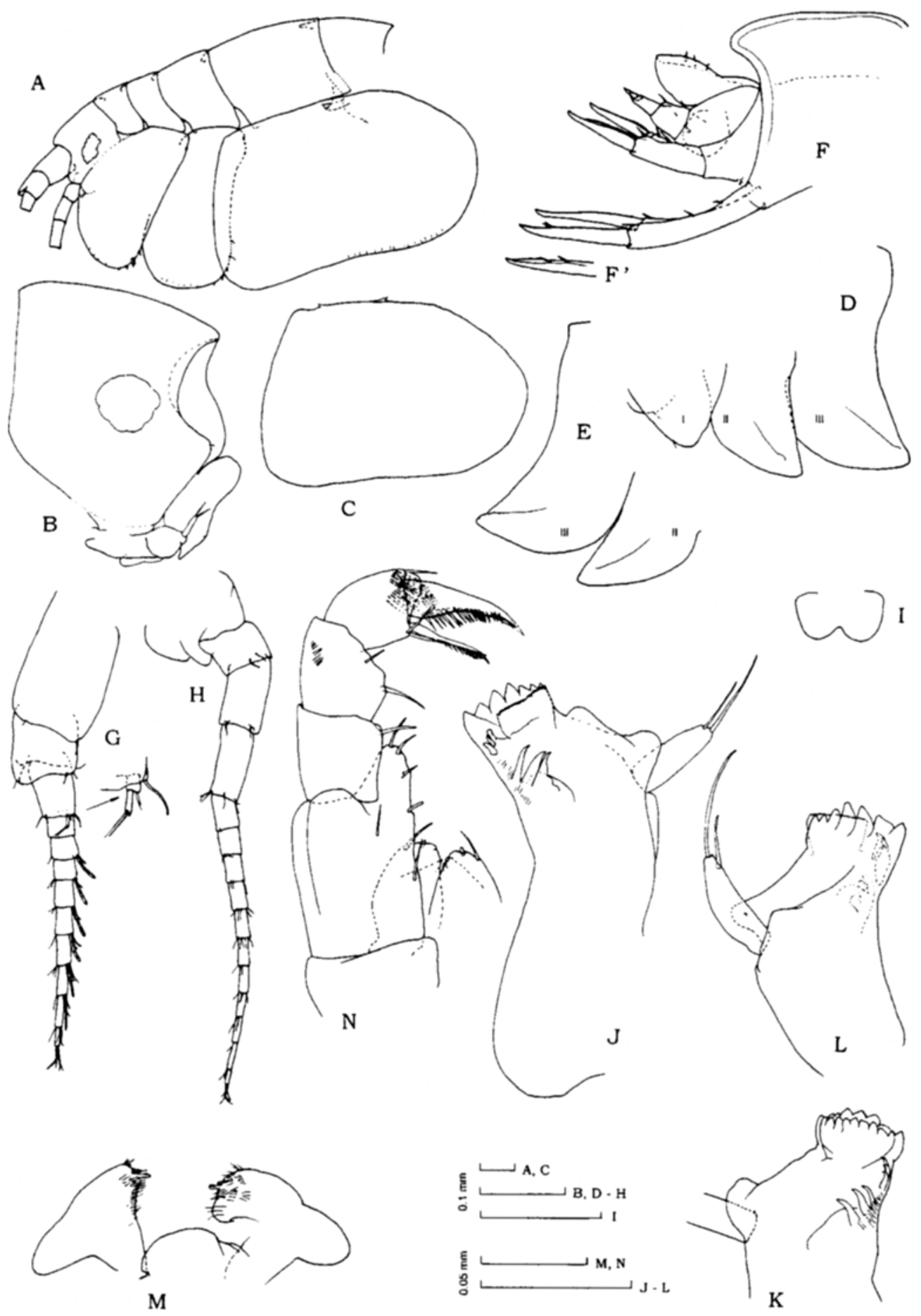


ner edge of basal segment of maxillipedal palp, the flat and spinose telson in $R$. rongo, in comparison with the spoon-like curved and marginally stiffened, poorly setiferous in $R$. dertoo, $R$. noko and $R$. judithae. Moore (op. cit.) confirms Barnard's (1974) conclusion that the importance of the nasiform process on antenna 1 (then known within Raumahara in the species $R$. noko and $R$. judithae) has no importance in generic separation.

The species $R$. dertoo, $R$. rongo, $R$. noko, and $R$. judithae are known from the temperate South Australian regions, while $R$. carinata has an Arctic distribution (Alaska). Reinvestigation is needed (cf. Barnard, 1974: 160), if the assignment of this species to Raumahara is to be justified: peraeonite 4 is prominently longer than in the other species; urosomites 2 and 3 should be coalesced (vs. free); maxilla 1 palp uniarticulate (vs. biarticulate); gnathopod 1 subchelate, palma oblique (vs. chelate), and carpus strongly lobate (vs. barely or not lobate).

As acknowledged by Barnard \& Karaman (1991: 684), the stenothoids are artificially separated into genera on the basis of mouthpart features, the presence of an accessory flagellum, and the breadth of article 2 of peraeopods 5-7, but little attention has been paid to the structure of gnathopods or other - not yet tried - characters. Considering this and the above mentioned mosaic of different states in phyletically important characters, the actual genus Raumahara may include at least three distinct groups, namely (1) $R$. dertoo, $R$. noko, $R$. judithae, (2) $R$. rongo, and (3) $R$. carinata. The significance of a mandibular palp has not been regarded herewith.

Within the first group, mainly constituted on the chelate gnathopods 1,2 and the horizontal, spoon-like telson, $R$. noko shows a plesiomorphic state in the following characters: a biarticulate accessory flagellum; antenna 2 third article short, not inflated; a rudimental mandibular palp; four apical setae on the outer plate of maxilla 2, and a second ramus article ("heavy spine", cf. Barnard, 1974: 13) on uropod 3. R. noko has in common with $R$. judithae the biarticulate accessory flagellum, and also the dorsally produced second article of antenna 1 (an apomorphic character). Further apomorphic character states in $R$. judithae are the reduced number of apical setae (three) on maxilla 2 outer plate, and above all the two-articulate uropod 3 (cf. Moore, 1981). $R$. dertoo, too, shows apomorphic character states on these appendages: two apical setae on outer plate of maxilla 2, and on uropod 3 only a seta instead of a second ramus article.

Within the typical "thaumatelsonins", Raumahara differs prominently in having a horizontally inserted telson and almost no modification of the urosome (cf. Barnard, 1972 b: 160). Concerning that character complex, Raumahara shows resemblance to Pseudothaumatelson Schellenberg, 1931 as well as to Thaumatelsonella Rauschert \& Andres, 1991, indicated by the dorsal extension of urosomite 1, the spade-like, horizontal telson, and normal uropods. The two genera, however, are discriminated by subchelate gnathopods and the presence of a fully developed mandibular palp. There is also a close similarity to Prothaumatelson Schellenberg, 1931 concerning the gnathopods in $R$. rongo, but there are differences in the accessory flagellum (absent in Prothaumatelson), urosomites (urosomites 2 and 3 referred to be coalesced in Prothaumatelson, free in Raumahara), and

Fig. 2. ?Raumahara virdurorum sp. n. - B, D-H: holotype, female, ovig., $1.6 \mathrm{~mm}$. - J: paratype, female, $1.6 \mathrm{~mm}$. - A, C: paratype, sex?, $1.8 \mathrm{~mm}$ - A: maxilla 1. B: maxilla 1, outer plate, distal part. C: maxilla 2. D: gnathopod 1. E: gnathopod 2. F: peraeopod 3. G: peraeopod 5. H: peraeopod 7. I: telson 


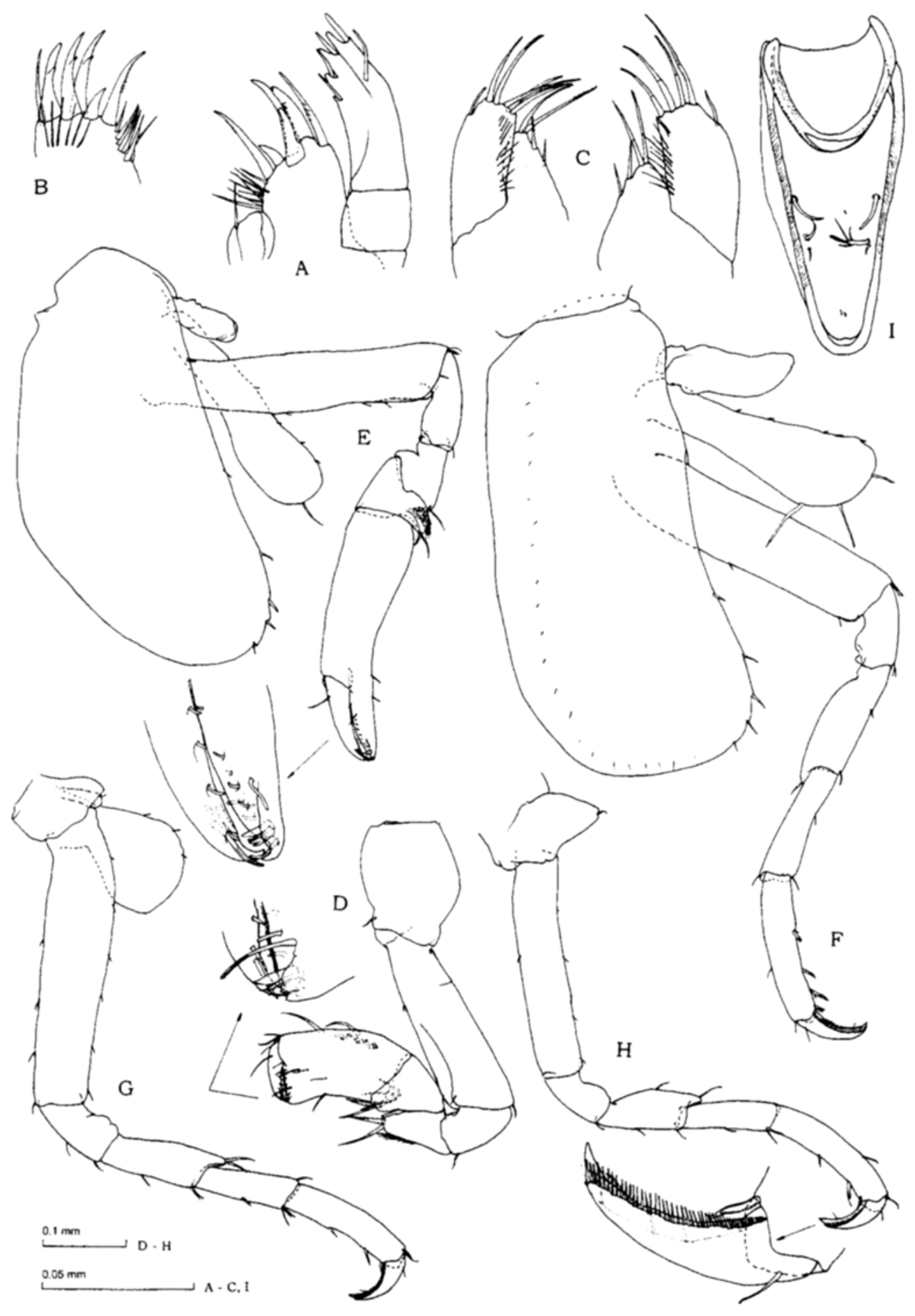


telson (in Prothaumatelson vertically inserted, laterally compressed, and huge, lateral surface area equal to lateral area of urosome fide Barnard \& Karaman, 1991: 697).

Though Chucullba Barnard, 1974 resembles Raumahara in the dorsally extended urosomite 1 and in the horizontal and spoon-like telson, an obvious distinction between these genera is to be seen in the slender, subchelate gnathopods of the former (vs. chelate), the strongly reduced uropod 3, and the prolongation of antenna 1 on first article (if present) and not on second article.

\section{?Raumahara virdurorum sp. $\mathrm{n}$. (Figs 1 and 2)}

Hol ot y pe : female, ovig. 1.6 mm; 3rd Dec. 1975. - ZMH K 38388; G. Hartmann \& G. Hartmann-Schröder leg.

Ty pe locality: South Australia, Steatford Bay, about $20 \mathrm{~km}$ to the south of Port Lincoln. Australian Collection - G. Hartmann \& G. Hartmann-Schröder 1975/76; Sta. 124.

P a r a t y p e s: 41 complete and some incomplete ind., 3rd Dec. 1975. - ZMH K 38389; G. Hartmann \& G. Hartmann-Schröder leg. - Locality as for holotype.

Additional material: Australian Collection-G. Hartmann \& G. Hartmann-Schröder:4 ind., 24th Dec. 1975, Sta. 143, Geelong, Pt. Londsdale, on abrasion terrace ahead of the lighthouse; ZMH K 38390.

Collection T. Krapp-Schickel: 5 ind., some incomplete. - Localities: Australia, Victoria, Cape Otway, W of Melbourne (4 ind.), and Port Philipp, S of Melbourne (1 ind.). Intertidal zone, wash of algae (Rhodophyceae, coralline, and epiphytes).

Et y m o log y: The specific name virdurorum is dedicated to the couple Dr. habil. Gesa Hartmann-Schröder and Prof. Dr. Dr. h.c. Gerd Hartmann, who collected abundant amphipod material, notwithstanding their interest in other very different groups. The specific name virdurorum refers to the scientists' latinized surname "Hartmann"; vir = Mann $($ Engl. $=$ man $)$, durus $=$ hart $($ Engl. $=$ hard $)$, the genitive case denoting that the material belonged to the "Hartmann collection".

Diagnose: Antenna 1 second article with nasiform process; mandible palp present, uniarticulate; gnathopod 1 subchelate, palm transverse; gnathopod 2 propodochelate, forcipate, dactylus about $1 / 3$ length of total propodus; urosomite 1 vaulting over urosomite 2; uropod 3 ramus biarticulate; telson spoon-like, horizontally inserted.

Description: Holotype, female, $1.6 \mathrm{~mm}$ (variations of different specimens in brackets): Body smooth. Peraeonite 4 about as long as PR $1+2+3$ [in ad.; in juv. PR 2+3]. Urosomites 1-3 free. UR 3 with dorsal hump vaulting over UR 2. - Head about as long as PR 1+2. Rostrum inconspicuous. Eyes: of stenothoid shape, normal. Lateral cephalic lobes shortly produced, rounded. Subantennal sinus not present. Mid-cephalic keel developed, strongly produced, rounded, separated from regularly rounded epistome by narrow groove. - Epimeral plate 2 more extensively produced posterodistally than EP 3.

Antenna 1 and 2 subequal. - A n te n n a 1 longer than head+PR $1+2$ (dorsal length). Peduncular art 1 and 3 without process, art 2 with nasiform process dorsomedially lextension depending on age, from scarcely longer than ventrally to reaching half art 3]. Length ratios of peduncular art 1:2:3 = 7:3:3. Accessory flagellum short, biarticulate; art 2 much narrower than basal art; art 1 with one seta, art 2 with two terminal setae. Flagellum subequal to peduncle, [7] 9 art, aesthetascs present. - A n t e n n a 2 : shape of peduncular art 3 subquadrate; art 4 and 5 subequal. Flagellum subequal to peduncle, [7] 11 art. Aesthetascs lacking.

Mouthparts. - Upper li p ventrally notched, lobes rounded. - M a n d i b le: Mdi well developed, with broad cusps. Lacinia mobilis on Md 1 broad, with major incisions, 
on Md r finely serrated. Raker (spine row) developed, 3 [4?] short spines, dentated terminally. Molar hump with 3 robust spines. Palp clearly developed, uniarticulate, about same length as Mdi, two setae apically. - L o w e r li $p$ : inner lobes coalesced; mandibular lobes well developed. - $\mathrm{M}$ axill a 1 : Ip one subapical seta. Op mediodistally setose, apically armed with 4 serrated, robust spines, 1 stout, simple spine, and 1 thin, short and stiff one. Palp biarticulate, length ratios 2:5 [or 3:5, depending on contusion of slide], extending beyond Op, with spines and teeth medio-apically. - Maxilla 2: plates tandem-grouped. Op extending Ip, apically $4-5$ setae, 1 on outer margin. Ip with 2 long apical setae, on inner margin 2 shorter, stiff ones mediodistally. - M axilliped: Ip reaching half ischium, 1 seta and 1 spine tooth apically. Op extending 50-75\% merus (= palp art 1); 2 setae apically, [0] 3 medially. Palp 4-articulate; length of merus to propodus subequal; art 3 (propodus) narrower than art 2; propodus distally furry; inner margin of dactylus strongly combed.

G n a th op od 1 subchelate, shorter than Gn 2. Coxa reduced, subquadrate, covered by Coxa 2. Basis weakly channelled distoanteriorly with translucid lobe. Merus rounded posterodistally, about as long as triangular carpus, which is slightly produced between merus and propodus. Propodus rectangular, anterior margin slightly convex with two setae, posterior margin concave; length:breadth about 2:1. Palm transverse, finely pectinate proximally, distally serrated, additionally armed with lateral and medial spines; palmar corner defined by a pair of robust spines. Dactylus as long as palm; inner margin finely pectinate and armed with spines. - G n a th o p od 2 propodochelate, forcipate. Coxa expanded, longer than basis, anterior margin regularly convex, posterior one nearly straight, ventrally rounded; posterior and posteroventral margin with isolated spines. Ischium longer than merus. Carpus subtriangular; lobe with dense, short setae, distoapically 2 longer ones. Propodus slender, length ratio of dactylus : total propodus = $33 \%$, terminally a hooked cusp and notch, defined by one pair of spines; palm armed with small spines. Dactylus also terminally hooked, matching well with the propodal notch; inner margin with small spines.

Perae opods 3 and 4 slender, subequal, but carpus in P 4 longer. Dactylus about half propodus length, hind margin with prominent setal comb outside and inside. Coxa 3 more than twice as deep as broad; postero-distally some spines. Coxa 4 dominant; wider than deep [getting wider with age ]; front margin slightly convex, ventral margin very slightly concave [or straight], posterior margin strongly convex; depth anteriorly and posteriorly subequal.

Pera e o ods 5 to 7 slender, length ratios of corresponding art only slightly different [ratio basis : propodus in smaller specimens about 1.3, in large ones up to 2.0]. Coxa 5 to 7 short. Coxa 5 trapeziform, weakly produced posteriorly. Coxa 6 oblong, roundly produced posteriorly. Coxa 7 blunt. Dactylus with prominent setal comb on anterior margin outside and inside.

Gills and oostegites on P 2 to P 5 (in P 6 and P 7 not found).

Uropods 1 to 3 extending less far caudad in succession. - U r o p od 1 : peduncle longer than subequal rami [peduncle subequal to subequal rami], peduncle scarcely spinose dorsolaterally and -medially; only outer ramus (the longer extending and more distally inserted one) with two spines [one]; both rami dorsolaterally and -medially very finely pectinate. - Uropod 2: peduncle as long as outer ramus; inner ramus a little shorter than outer ramus, inserted more proximally; both rami with same fine pectination 
as Up 1. - Uropod 3: peduncle + ramus about as long as peduncle of Up 2; peduncle sub-equal to biarticulate ramus, apicodorsally one stiff seta; art 1 longer than art 2, one seta terminally; art 2 strong, like a nail ("heavy spine" after Barnard).

Te l s on reaching end of Up 3 ramus art 1 , longer than twice the breadth (if measured from the very basal part, which is situated under the vaulted UR 1 and fused with UR 3 medially; see figs), distad tapering, apex rounded, spoon-like, dorsolaterally and basally sclerotic clasps, poorly setiferous.

Geographical distribution: Southern Australia, from Port Lincoln (South Australia, W of Adelaide) to Cape Otway (Victoria, W of Melbourne).

E c o l o g y : Intertidal, wash of algae (mostly Rhodophyceae including coralline and epiphytes).

Remarks: The discovered Raumahara-like species resembles conspicuously $R$. rongo (group 2) in the subchelate gnathopod 1, the produced mid-cephalic keel and the well developed, spiniform article 2 of uropod 3. Differences in the new species Raumahara virdurorum, however, are the presence of a mandibular palp, a spoon-like, barely setiferous telson, the dorsocaudad process on urosomite 1 , the dorsal process on antenna 1 article 2 and the biarticulate accessory flagellum. $R$. rongo is further discriminated by the following apomorphic characters: maxilla 1 inner plate smooth, the single subapical seta is lacking; more slender outer plate in maxilla 2, bearing only two apical setae.

While some characters of Pseudothaumatelson and Thaumatelsonella, e. $\mathrm{g}$. the mandibular palp, dorsocaudad process on urosomite 1, spade-like, poorly setiferous telson and normal uropods, show resemblences to the specimens studied, they are clearly distinguished by the chelate gnathopod 2 .

Barnard's statement (1974: 112) on the phyletic situation in Raumahara genus is still valid "... perhaps several genera will be found within Raumahara, but presently any division seems unwise as several more southern species may be found and certain other problems arise."

Acknowledgements. T. K.-S. expresses gratitude for the opportunity to work on the "Hartmann collection" at the Zoologisches Museum Hamburg, financed by a grant donated by the Universität Hamburg, as well as for the kind invitation by Dr. Gary Poore to be a guest for ten weeks at the Crustacean Department of the Victoria Museum, Melbourne.

\section{LITERATURE CITED}

Barnard, J. L., 1972 a. Gammaridean Amphipoda from Australia, Part 1. - Smithson. Contr. Zool. 103, $1-333$.

Barnard, J. L., 1972 b. The marine fauna of New Zealand: algae-living littoral Gammaridea (Crustacea Amphipoda). - Mem. N. Z. oceanogr. Inst. 62, 7-216.

Barnard, J. L., 1974. Gammaridean Amphipoda from Australia, Part 2. - Smithson. Contr. Zool. 139, $1-148$.

Barnard, J. L. \& Karaman, G. S., 1991. The families and genera of gammaridean Amphipoda (except marine gammaroids). - Rec. Aust. Mus. (Suppl.) 13 (1/2), 1-866.

Moore, P. G., 1981. Marine Amphipoda (Crustacea) new to science from the Tasmanian phytal fauna. - J. nat. Hist. 15, 939-964.

Rauschert, M. \& Andres, H. G., 1991. Thaumatelsonella kingelepha, eine neue Gattung und Art aus der Antarktis (Crustacea: Amphipoda: Gammaridea: Stenothoidae). - Helgoländer Meeresunters. 45, 225-235.

Schellenberg, A., 1931. Gammariden und Caprelliden des Magellangebietes, Südgeorgiens und der Westantarktis. - Further zool. Results Swed. Antarct. Exped. 2 (6), 1-290.

Shoemaker, C. R., 1955. Amphipoda collected at the Arctic Laboratory, office of Naval Research, Point Barrow, Alaska, by G. E. MacGinitie. - Smithson. misc. Collns. 128 (1), 1-78. 